\title{
Pemetaan Daerah Rawan Kebakaran Hutan dan Lahan Dengan Menggunakan Sistem Informasi Geografis (Studi Kasus: Kecamatan Bukit Batu, Kab. Bengkalis)
}

\author{
Ajriansyah Putra ${ }^{1}$, Ambar Tri Ratnaningsih ${ }^{2}$, Muhammad Ikhwan ${ }^{2}$ \\ ${ }^{1}$ Mahasiswa Fakultas Kehutanan Universitas Lancang Kuning \\ ${ }^{2}$ Staff Pengajar Fakultas Kehutanan Universitas Lancang Kuning \\ Jl. Yos Sudarso Km. 8 Rumbai. Pekanbaru \\ Email: putraansyah363@gmail.com,ambar@unilak.ac.id,dan mmighwan@yahoo.com
}

\begin{abstract}
ABSTRAK
This study aims to map the level of vulnerability of forest and land fires in an effort to support the realization of forest fire management strategy in Bengkalis Regency by considering land cover aspects, soil type, rainfall, height of place and settlement distance. This research was conducted in Bukit Batu sub-district, Kab. Bengkalis. This research uses survey method in collecting secondary data and primary data. The data analysis was done with each observation parameter. The results of this study indicate that the level of fire vulnerability in Bukit Batu Subdistrict is divided into two classes, namely very high and high vulnerability. Most of Bukit Batu sub-district has a very high level of vulnerability. High vulnerability area has 27,533,611 $\mathrm{Ha}$ $(22,49 \%)$ and very high $94,915,83(77,51 \%)$. Where the determining factor that plays a major role in influencing the high level of vulnerability in a location that is land cover, rainfall, and soil type.
\end{abstract}

Keywords: Mapping Areas, Forest Fire and Land, Geographic Information System.

\section{PENDAHULUAN}

Kabupaten Bengkalis adalah salah satu Kabupaten di Provinsi Riau yang Wilayahnya mencakup daratan bagian timur pulau Sumatera dan wilayah kepulauan dengan memiliki 8 kecamatan. Luas gambut yang dimiliki Kabupaten Bengkalis sebesar 269.760 hektar sehingga daerah ini sangat rentan terjadinya kebakaran hutan dan lahan terutama pada lahan gambut. Kebakaran hutan dan lahan di wilayah Kab Bengkalis masih terus berlanjut, titik api baru bermunculan di setiap hektar hingga kini 180 hektar lahan gambut di Bengkalis terbakar (BPDB, Suiswanto 2013 ).

Kebakaran hutan dan lahan merupakan salah satu bentuk gangguan yang semakin sering terjadi. Dampak negatif yang ditimbulkan oleh kebakaran hutan cukup besar mencakup kerusakan ekologis, menurunnya keanekaragaman hayati, merosotnya nilai ekonomi hutan dan produktifitas tanah, perubahan iklim mikro maupun global, dan asapnya mengganggu transportasi baik darat, laut dan udara. Mengingat dampak 
kebakaran hutan tersebut, maka upaya perlindungan terhadap kawasan hutan sangatlah penting. Untuk mencegah terjadinya kebakaran hutan dan lahan perlu adanya suatu peta yang menyatakan daerah yang rawan terhadap kebakaran hutan dan lahan dengan pertimbangan aspek penutupan lahan, jenis tanah, curah hujan, ketinggian tempat dan jarak pemukiman.

Tujuan penelitian adalah untuk memetakan tingkat kerawanan kebakaran hutan dan lahan dalam upaya mendukung terwujudnya strategi penanggulangan kebakaran hutan di daerah Kabupaten Bengkalis dengan mempertimbangkan aspek penutupan lahan, jenis tanah, curah hujan, ketinggian tempat dan jarak pemukiman.

\section{METODE PENELITIAN}

Penelitian ini dilaksanakan di wilayah Kecamatan Bukit Batu Kabupaten Bengkalis. Penelitian ini dilaksanakan selama 6 bulan yaitu dari bulan Januari Juli 2017. Adapun bahan yang digunakan dalam penelitian ini adalah Peta Penutupan Lahan tahun 2013, Data Curah Hujan, Peta Ketinggian, Peta Sebaran Lahan Gambut, Peta Lokasi Pemukiman, Peta Batas Administrasi, Peta Jaringan Jalan
Bengkalis, Peta Sebaran Izin Usaha Pemanfaatan Hasil Hutan Kayu (IUPHHK) Provinsi Riau, Data Sebaan Hotspot Tahun 2014-2016. Sedangkan alat yang digunakan adalah personal computer (pc), Software Arcgis 10.3, GPS, dan Kamera digital.

Penelitian ini menggunakan metode survei. Metode survei adalah metode yang bertujuan untuk mengumpulkan data dari lembaga. Data yang di kumpulkan terdiri dari data primer dan data sekunder. Pengumpulan Data sekunder meliputi perolehan data spasial, kodifikasi data, penyeragaman sistem proyeksi peta, konversi format data sesuai dengan perangkat lunak yang dipakai dalam menjalankan prosedur Sistem Informasi Geografis (SIG). Sedangkan data primer berupa melakukan memverifikasi keberadaan dan kondisi kawasan yang dianggap berpotensi menjadi daerah rawan kebakaran hutan dan lahan.

\section{Pengolahan Data}

\section{Pengkelasan Masing-masing peubah}

Setelah semua data spasial dimasukkan kedalam komputer dalam bentuk peta digital, kemudian dilakukan pemasukan data atribut dan pembobotan pada setiap parameter. 
Parameter-parameter yang digunakan untuk menetukan tingkat kerawanan adalah penutupan lahan (landcover), curah hujan, ketinggian tempat, jenis.

\section{1) Penutupan Lahan}

Untuk tipe vegetasi atau penutupan lahan pemberian bobot dilakukan dengan berdasarkan kepada kepekaan tipe vegetasi yang bersangkutan terhadap terjadinya kebakaran. Nilai bobot 1 diberikan kepada tipe vegetasi yang sangat peka yaitu yang sangat mudah terbakar, sampai nilai 7 untuk yang sulit terbakar.

Disini pembobotan mengacu pada klasifikasi dan pembobotan yang dilakukan oleh Rucker (2002), Hoffman(2000) serta Barus dan Gandasasmita(1996).

Tabei 2 Tpe regtasi atal turpan laban dan pembobotanya

\begin{tabular}{|c|c|c|}
\hline Tipe Tegetasi atau Penutupan Lahne & Kelas & Babot \\
\hline Belukar & 1 & \\
\hline Bellikr Ravia & 2 & \\
\hline Hutan Mengrone Priner & 6 & \\
\hline Hutan Mangrove Selmoder & 5 & \\
\hline Huttan L ahan Kering Primer & 4 & \\
\hline Hutan Lahan Kering Sekmjer & 2 & \\
\hline Hutan Tanaman Intratni & 2 & \\
\hline Hutan Rana Sehunder & 3 & \\
\hline Hutan Rawa Primer & 4 & 30 \\
\hline Periblowan & 3 & \\
\hline Pertanian Lahan Kering & 1 & \\
\hline $\begin{array}{l}\text { Pertanian Iahan Kering Bercampur } \\
\text { dengan Senak }\end{array}$ & 2 & \\
\hline Tambak & 7 & \\
\hline Tanah Tertoda & 7 & \\
\hline Pertambangan & 6 & \\
\hline Perrioiman Transmigrasi & 1 & \\
\hline
\end{tabular}

Sumber : Ruscker (2002), Barus dan Gandasemita(1990), dan Hoffinan (2000)

\section{2) Jenis Tanah}

Pembuatan peta kerawanan kebakaran hutan berdasarkan jenis tanah terdapat 2 kelas. Peta jenis tanah tersebut menganalisis dengan menggunakan sistem skoring. Klasifikasi skoring berdasarkan sifat atau karakteristik dari setiap jenis tanah gambut dan non gambut. Pembuatan skoring untuk jenis tanah disajikan pada tabel 3 .

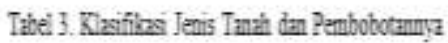

\begin{tabular}{|c|c|c|}
\hline Jeais Tamh & Kelas & Bobot \\
\hline Gamint & 1 & \\
\hline Na Gamber: & 2 & $\Delta$ \\
\hline
\end{tabular}

\section{3) Curah Hujan}

Klasifikasi curah hujan dilakukan berdasarkan tipe iklim di daerah kabupaten Bengkalis. Untuk wilayah yang paling kering akan lebih sensitif untuk terbakar, khususnya pada waktu musim kemarau dan diberi nilai bobot 1 , sedangkan wilayah yang paling basah tidak akan mudah terbakar walaupun mengalami musim kemarau yang panjang. Hasil klasifikasi dan pembobotan curah hujan dapat dilihat pada tabel 4 dibawah ini.

Tabel 4. Kasifikasi Curah Hujan Bulanan dan Pembobotannya

\begin{tabular}{|c|c|c|}
\hline Curnh Hujan Tahuman(mm) & Kelas & Bobot \\
\hline 500 & I & \\
$501-1000$ & 2 & 25 \\
$1001-1500$ & 3 & \\
$1501-2000$ & 4 & \\
$>2000$ & 5 & \\
\hline
\end{tabular}




\section{4) Ketinggian Tempat (mdpl)}

Ketinggian tempat dari permukaan laut diperoleh dari hasil derivasi Digital Elevation Model (DEM) resolusi 25 meter. Ketinggian tempat di atas permukaan laut diklasifikasikan dan diberi nilai bobot. Pada tempat-tempat yang rendah dikatakan mempunyai potensi yang tinggi untuk mudah terbakar dan diberi nilai bobot 1 , seterusnya pada tempat yang lebih tinggi akan lebih sulit terbakar, sampai pada tempat tertinggi diberibobot 6 . Untuk klasifikasi ketinggian tempat dan nilai bobotnya dapat dilihat pada tabel 5 .

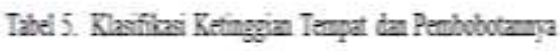

\begin{tabular}{|c|c|c|}
\hline Ketingsin Tenpat & Kehs & Bobot \\
\hline$<40$ & 1 & \multirow{6}{*}{10} \\
\hline$>40.90$ & 2 & \\
\hline$>90-130$ & 3 & \\
\hline$>130-229$ & 4 & \\
\hline$>220-500$ & 5 & \\
\hline$>500$ & 6 & \\
\hline
\end{tabular}

\section{5) Jarak dari Pemukiman}

Peta jarak diperoleh dari proses buffering data lokasi pemukiman dengan menggunakan perangkat lunak ArcGis. Peta batas pemukiman dalam bentuk Shapefile diolah dengan menggunakan fitur create buffer pada menu theme sehingga diperoleh peta jarak dari pemukiman (Nuarsa, 2005).
Berdasarkan informasi yang diperoleh dari penelitian Arianti (2006), jarak tempuh terjauh yang dapat dicapai oleh manusia adalah $\pm 4 \mathrm{~km}$. Informasi ini dijadikan sebagai dasar untuk membagi kelas jarak pemukiman.

Tabel 6. Klasifikasi jarak dari pemukiman dam pembobotannya

\begin{tabular}{|l|c|c|}
\hline Jarak dari pemukiman $(m)$ & Kelas & Bobot \\
\hline $0-1000$ & 1 & \\
$>1000-2000$ & 2 & 10 \\
$>2000-3000$ & 3 & \\
$>3000-4000$ & 4 & \\
$>4000$ & 5 & \\
\hline
\end{tabular}

\section{Pembuatan Peta Kelas Kerawanan Kebakaran}

Peta rawan kebakaran merupakan model spasial yang digunakan untuk mempersentasekan kondisi dilapangan terkait dengan resiko terjadinya kebakaran hutan dan lahan. Model ini dibuat dengan menggunakan aplikasi GIS untuk memudahkan proses overlay antar faktor-faktor penyebab kebakaran. Oleh karena itu, memahami faktor-faktor penyebab dan prilaku kebakaran merupakan hal yang sangat utama didalam melakukan pemodelan ini (Solichin, dkk, 2007).

Rawan Kebakaran:

$\{30 \%$ * (Penutupan Lahan $)\}+\{25 \%$ * (jenis Tanah) $\}+\{25 \%$ (Curah Hujan) $\}+$ $\{10 \%$ * (Ketinggian Tempat $)\}+\{10 \%$ * 
(Jarak Pemukiman)\} (Solichin, dkk, 2007).

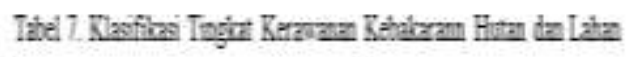

\begin{tabular}{|c|c|}
\hline Tinghat Kerrumana & Kehs \\
\hline Sangt Tinggi & $212-310$ \\
\hline Tinge & $311-396$ \\
\hline Setang & 397482 \\
\hline Readiah & $483-568$ \\
\hline
\end{tabular}

Suber : Hasi pehtragn bedercian nums Suggs

\section{HASIL DAN PEMBAHASAN}

\section{Faktor-Faktor Penyebab Kebakaran}

Hutan dan Lahan di Kecamatan Bukit

\section{Batu}

\section{1) Tutupan Lahan}

Pada Kecamatan Bukit Batu diketahui jenis tutupan lahan yaitu belukar, belukar rawa, hutan lahan kering sekunder, hutan mangrove sekunder, hutan rawa primer, hutan rawa sekunder, hutan tanaman, perkebunan, pemukiman, pertambangan, pertanian lahan kering, pertanian lahan kering campur, rawa, tanah terbuka, dan tubuh air (gambar 2). Adapun jenis tutupan lahan yang terdapat di Kecamatan Bukit Batu disajikan pada Tabel 9.

Tabel 9. Tutupan Lahan di Kecamatan Bukit Batu
\begin{tabular}{|r|l|r|r|}
\hline No & Tutupan Lahan & Luas & Persentase \\
\hline 1 & Belukar & $3.538,7$ & $2,89 \%$ \\
\hline 2 & Belukar rawa & $21.732,2$ & $17,76 \%$ \\
\hline 3 & Hutan lahan kering sekunder & 7,3 & $0,01 \%$ \\
\hline 4 & Hutan Mangrove sekunder & 181,2 & $0,15 \%$ \\
\hline 5 & Hutan rawa primer & 5,7 & $0,005 \%$ \\
\hline 6 & Hutan rawa sekunder & $24.658,0$ & $20,15 \%$ \\
\hline 7 & Hutan tanaman & $26.759,6$ & $21,86 \%$ \\
\hline 8 & Perkebunan & $9.362,8$ & $7,65 \%$ \\
\hline 9 & Pemukiman & 22,2 & $0,02 \%$ \\
\hline 10 & Pertambangan & 608,7 & $0,50 \%$ \\
\hline 11 & Pertanian lahan kering & 622,8 & $0,51 \%$ \\
\hline 12 & Pertanian lahan kering campur & $6.494,1$ & $5,31 \%$ \\
\hline 13 & Rawa & 387,7 & $0,32 \%$ \\
\hline 14 & Tanah terbuka & $27.957,0$ & $22,84 \%$ \\
\hline 15 & Tubuh air & 51,4 & $0,04 \%$ \\
\hline Jumlah & $\mathbf{1 2 2 . 3 8 9 , 4}$ & $\mathbf{1 0 0 \%}$ \\
\hline Sumber:BPDAS HL Indragiri-Rokan, 2017 & & \\
\hline
\end{tabular}

Menurut Rusdiayanti (2000) 90\% penyebab kebakaran hutan adalah (1) karena perbuatan manusia secara sengaja misalnya pembukaan lahan (land clearing) dengan cara untuk keperluan perkebunan, pengembangan Hutan Tanaman Industri dan pemukiman transmigrasi serta perladangan berpindah oleh masyarakat sekitar hutan dan (2) karena faktor ketidak sengajaan.

\section{2) Jenis Tanah}

Jenis tanah yang mendominasi daerah Kecamatan Bukit Batu adalah tanah gambut seluas 103.741,5 $\mathrm{Ha}$ $(84,78 \%)$ dan tanah non gambut seluas 18.617,6 Ha (15,22\%). Gambut merupakan indikator ketersediaan bahan bakar pada lahan gambut. Oleh karena itu, semakin tebal lapisan gambut pada suatu areal, maka semakin besar pula ketersediaan bahan bakar.

Tabel 10. Jenis Tanah di Kecamatan Bukit Batu

\begin{tabular}{|c|c|c|c|}
\hline $\mathrm{N}_{0}$ & Jenis Tanah & Luas $(\mathrm{Ha})$ & Persentase \\
\hline 1 & Non Gambut & $18.617,6$ & $15,22 \%$ \\
\hline 2 & Gambut & $103.741,5$ & $84,78 \%$ \\
\hline & Jumlah & 122.359 & $100 \%$ \\
\hline
\end{tabular}

\section{3) Ketinggian Tempat}

$$
\text { Menurut Solichin }
$$

menyatakan faktor ketinggian tempat dan aksesibilitas mempunyai pengaruh yang kuat dalam kejadian kebakaran. 
Daerah dengan ketinggian $<100 m$ merupakan dengan kondisi topografi yang datar serta dapat diakses menjadi alasan utama terjadinya kegiatan perladangan dan pembukaan hutan oleh manusia dengan persiapan lahan secara membakar. Berdasarkan peta ketinggian tempat, Kecamatan Bukit Batu berada pada ketinggian $<40 \mathrm{~m}$ diatas permukaan laut.

\section{4) Curah Hujan}

Menurut Solichin (2004), iklim atau perubahan cuaca bukanlah penyebab utama terjadinya kebakaran. Namun tingkat kekeringan yang terjadi akibat perubahan iklim sangat berpotensi meningkatkan terjadinya kebakaran di wilayah tertentu yang menggunakan api untuk pengelolaan lahan.

\begin{tabular}{|c|c|c|}
\hline Bulan & Curah Hujan & HariHujan \\
\hline Ianuari & 50,7 & 9 \\
\hline Fehruari & 127 & 4 \\
\hline Maret & 38 & 3 \\
\hline Asril & 77,4 & 10 \\
\hline Mei & 87,1 & 11 \\
\hline Ini & 5 & 1 \\
\hline Infif & 12,5 & 4 \\
\hline Agrants & 42,7 & 12 \\
\hline September & 58,3 & 13 \\
\hline Ortober & 67 & 13 \\
\hline November & 260,5 & 16 \\
\hline Desemer & 106,4 & 12 \\
\hline Jumlah & 818,3 & 108 \\
\hline
\end{tabular}

Berdasarkan tabel 11 diperoleh jumlah curah hujan yaitu $818,3 \mathrm{~mm} / \mathrm{thn}$. Kejadian kebakaran hutan cenderung lebih banyak terjadi pada saat curah hujan terendah karena pada saat curah hujan rendah menyebabkan bahan bakar potensial lebih cepat terbakar.

\section{5) Jarak dari Pemukiman}

Kemampuan jarak tempuh yang dapat dicapai oleh manusia untuk beraktivitas dilahan gambut maka semakin besar alasan penyebab ternyadinya kebakaran yang disebabkan oleh aktivitas manusia baik yang dilakukan secara sengaja maupun tidak sengaja. Seperti yang dikutip dalam Bowen (2000) yang menyatakan bahwa semua kebakaran yang terjadi di Kalimantan, Sumatera dan Irian Jaya disebabkan oleh manusia sedangkan kebakaran yang disebabkan oleh petir sangat jarang terjadi pada kondisi seperti di Indonesia.

Tabel 12 Jark Lokasi Penukiman Terbadap Tutupan Iahan di Kecamatan Bukt

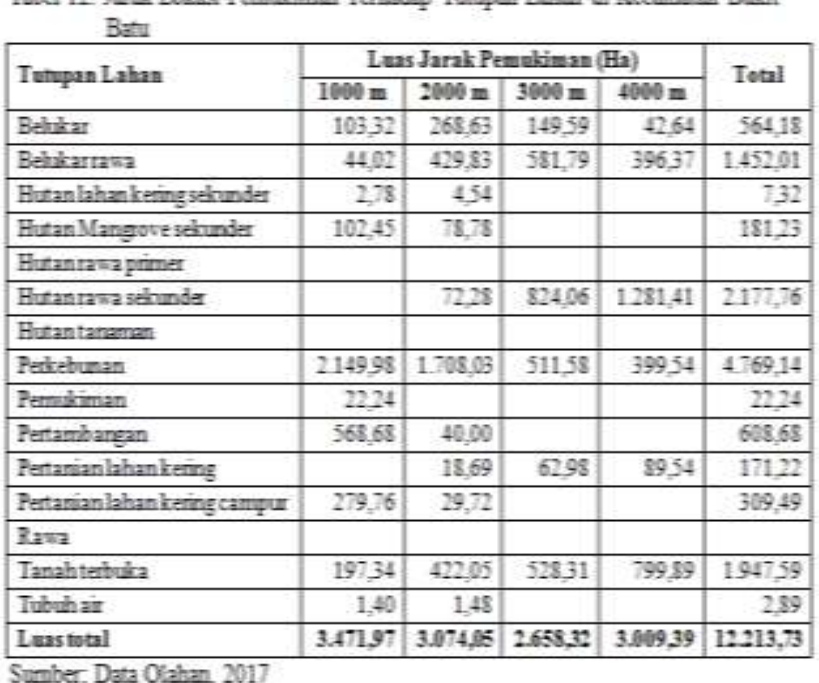

Adapun jarak tempuh terluas yaitu terdapat pada jarak $1000 \mathrm{~m}$ dengan luasan 2.149,98 ha dan tutupan lahan 
perkebunan. Sementara luas jarak tempuh terkecil terdapat pada jarak $1000 \mathrm{~m}$ dengan luasan 1,40 ha pada pola penggunaan lahan yaitu tubuh air. Jarak tempuh yang dekat memberikan peluang yang cukup besar kepada masyarakat dalam melakukan kegiatan pengolahan lahan dan pembukaan hutan.

\section{Sebaran Hotspot}

Berdasarkan Permenhut No.P12//P Menhut-II/2009 pasal 1 menyatakan bahwa titik panas (Hotspot) adalah indikator kebakaran hutan yang mengindikasikan suatu lokasi yang memiliki suhu relatif tinggi dibandingkan suhu disekitarnya. Oleh karena itu, titik hospot sering dijadikan sebagai acuan utama dalam mengetahui suatu lokasi yang rawan akan terjadina kebakaran. Berdasarkan tabel 13 diperoleh sebaran jumlah titik hotspot pada tahun 20142016.

\begin{tabular}{|c|c|c|c|c|c|}
\hline \multirow{2}{*}{$\mathrm{N}_{0}$} & \multirow{2}{*}{ Tutupan Lahan } & \multicolumn{3}{|c|}{ Tahun } & \multirow{2}{*}{ Total } \\
\hline & & 2014 & 2015 & 2016 & \\
\hline 1 & Betukar & 30 & 4 & - & 34 \\
\hline 2 & Belukar rawa & 121 & 7 & 11 & 139 \\
\hline 3 & Hutan lahan kering seksunder & - & - & - & - \\
\hline 4 & Hutan Mangrove seisunder & - & - & - & - \\
\hline 5 & Hutan rawa primer & - & - & - & - \\
\hline 6 & Hutan rawa seiminder & 110 & 2 & - & 112 \\
\hline 7 & Hutan tanaman & 208 & 5 & 31 & 244 \\
\hline 8 & Perkebunan & 28 & 1 & 12 & 41 \\
\hline 9 & Pemuliman & - & - & - & - \\
\hline 10 & Pertambangan & - & - & - & - \\
\hline 11 & Pertanian lahan kering & 10 & 1 & - & 11 \\
\hline 12 & Pertanian lahan kering campur & - & - & - & - \\
\hline 13 & Rawa & - & - & - & - \\
\hline 14 & Tamah terbuka & 158 & 25 & 111 & 294 \\
\hline 15 & Tubuh air & - & - & - & - \\
\hline \multicolumn{2}{|c|}{ Total } & 665 & 45 & 165 & 875 \\
\hline
\end{tabular}

Pada tabel 13 diketahui sebaran hotspot tertinggi terdapat pada tutupan lahan tanah terbuka, hutan tanaman, belukar rawa dan hutan rawa sekunder. Tingginya sebaran hotspot pada berbagai jenis tutupan lahan tersebut dapat disebabkan karena kondisi fisik yang kering dari vegetasi itu sendiri. Hal tersebut dapat disebabkan dampak dari tingginya suhu dan kelembaban yang rendah pada lingkungan dimana vegetasi tersebut tumbuh. Kondisi yang kering pada vegetasi akan berdampak pada mudahnya vegetasi mengalami kebakaran. Menurut Anderson et al (1999) dalam Sabaradji (2000) bahwa jenis vegetasi padang rumuput dan semak belukar tingkat bahaya kebakarannya sangat tinggi.

\section{Tingkat Kerawanan Kebakaran Hutan dan Lahan}

Untuk mengetahui zone-zone rawan kebakawan hutan dan lahan di wilayah Kecamatan Bukit Batu dilakukan dengan tumpang susun terhadap peta penutupan lahan/vegetasi, peta ketinggian tempat/elevasi, peta sebaran curah hujan, peta jenis tanah, dan peta jarak pemukiman.

Tabel 14. Peta Tingkat Rawan Kebakaran di Kecamatan Bukit Batu

\begin{tabular}{|c|c|c|}
\hline Tingkat Kerawanan & Luas (Ha) & Persentase \\
\hline Sangat Tinggi & $94.915,8346$ & $77,51 \%$ \\
\hline Tinggi & $27.533,6111$ & $22,49 \%$ \\
\hline Jumlah & $122.449,4457$ & $100 \%$ \\
\hline
\end{tabular}


Dari tabel 14 menunjukkan bahwa sebagian besar daerah Kecamatan Bukit Batu memiliki tingkat kerawanan sangat tinggi seluas 94.915,83 (77,51\%) dan tingkat kerawanan tinggi seluas $27.553,61$ (22,49\%). Tingkat kerawanan kebakaran lahan yang sangat tinggi dan tinggi pada Kecamatan Bukit Batu dapat disebabkan aktivitas masyarakat yang meningkat terutama pada lahan belukar rawa, hutan rawa sekunder, hutan tanaman dan tanah terbuka yang memiliki hotspot terbanyak.

\section{Land Unit Kecamatan Bukit Batu}

Hasil overlay yang dilakukan, diperoleh sebanyak 88 land unit di Kecamatan Bukit Batu. Adapun peta sebaran land unit Kecamatan Bukit Batu terdapat pada lampiran 8. Berdasarkan tabel 15 diketahui land unit terluas yaitu pada land unit 58 dengan tutupan lahan hutan tanaman, jenis tanah gambut, ketinggian < 40, curah hujan 818,3 $\mathrm{mm} /$ tahun, dan jarak aktivitas pemukiman > $4000 \mathrm{~m}$ yaitu seluas $26.678,9188$ ha. Sedangkan land unit terkecil yaitu pada land unit 2 dengan tutupan lahan perkebunan, jenis tanah nongambut, ketinggian $<40 \mathrm{~m}$, curah hujan 818,3 mm/thn, dan jarak pemukiman $>4000$ seluas 0,00002 ha.

\section{Pengamatan Lapangan}

Pengamatan lapangan bertujuan untuk mengetahui kondisi lapangan yang sebenarnya terutama pada daeradaerah rawan kebakaran yang ada di lokasi pengamatan. Dari hasil pengamatan yang dilakukan diketahui bahwa daerah yang masuk dalam kelas rawan sangat tinggi dapat dijumpai adanya vegetasi alang-alang, pakispakisaan, sawit dan tumbuhan bawah lainnya. Tingginya rawan kebakaran yang diperoleh berdasarkan hasil analisis juga didukung dengan tutupan lahan yang merupakan rentan terhadap kebakaran.

\section{KESIMPULAN DAN SARAN \\ Kesimpulan}

Tingkat kerawanan kebakaran di Kecamatan Bukit Batu terbagi atas dua kelas yaitu rawan sangat tinggi dan rawan tinggi. Sebagian besar daerah Kecamatan Bukit Batu memiliki tingkat kerawanan sangat tinggi. Daerah kerawanan tinggi memiliki luas $27.533,611 \mathrm{Ha}(22,49 \%)$ dan sangat tinggi $94.915,83(77,51 \%)$. 


\section{Saran}

Hasil pengamatan tingkat kerawanan kebakaran hutan dan lahan menunjukkan bahwa seluruh areal pada Kecamatan Bukit Batu merupakan daerah dengan tingkat kerawanan sangat tinggi sekali. Oleh karena itu, disarankan melakukan penelitian yang mendalam untuk lebih mengetahui faktor penyebab tingginya tingkat kerawanan kebakaran hutan dan lahan.

\section{DAFTAR PUSTAKA}

Ruecker, G, 2002. Consulting and Software Development to Produce a Dinamic Fire Danger Map for East Kalimantan. IFFM Documnet Report(Temporary).

Solichin. 2004. "Hotspot" Tidak Selalu Titik Kebakaran. Newsletter Hotspot. South Sumatera Forest Fire Project Uni Eropa. Departemen Kehutanan. Pemerintah Propinsi Sumatera Selatan.

Solichin, L. Tarigan, P. Kimman, B. Firman, dan R. Bagyono. 2007. Pemetaan Daerah Rawan Kebakaran.

Suyanto, Unna C, Prianto W.2003. Kebakaran di Lahan Rawa atau Gambut di Sumatera Selatan: Masalah dan Solusi. Center for International Forestry Reserch. Jakarta. 